\title{
Cantú Syndrome with panhypopituitarism
}

\author{
Liu John ${ }^{1}$, Khangura Darshan ${ }^{2 *}$ and Kurukulasuriya L Romayne ${ }^{2}$ \\ ${ }^{1}$ Department of Medicine, University of Missouri, USA \\ ${ }^{2}$ Division of Endocrinology, Diabetes and Metabolism, Department of Medicine, University of Missouri, USA
}

\section{Introduction}

Cantú syndrome is a rare autosomal dominant genetic disorder characterized by cardiomegaly, hypertrichosis and osteochondrodysplasia initially described in 1982 [1]. In addition to the disease-defining signs and symptoms, Cantú syndrome has also been associated with a variety of less common phenotypical manifestations. Coarse facies, similar to that seen in patients with acromegaly is often part of the clinical presentation. We describe a case of a patient with acromegaloid features who unexpectedly also had panhypopituitarism and was ultimately diagnosed with Cantú syndrome by genetictesting. The innovations in genetic testing have made the diagnosis of this disorder possible, which was not available when the patient first presented.

\section{Case description}

The patient is a 57 -year-old female who came to our attention after presenting to the medical intensive care unit with hypotension. A cortisol level drawn at midnight was decreased at $2.38 \mathrm{mcg} / \mathrm{dL}$ and the patient was treated for adrenal insufficiency. Biochemical evaluation was suspicious for central adrenal insufficiency with inadequate response to cosyntropin stimulation from $2.82 \mathrm{mcg} / \mathrm{dL}$ at baseline to $7.98 \mathrm{mcg} / \mathrm{dL}$ at 1 hour. A cortisol level of $18 \mathrm{mcg} / \mathrm{dL}$ or greater either at 30 minutes or 1 hour is considered an adequate response to cosyntropin. An adrenocorticotropic hormone (ACTH) level was not drawn this admission nor was it done with the cosyntropin stimulation test. She was also found to have central hypothyroidism with a thyroid stimulating hormone (TSH) $2.17 \mathrm{mcunit} / \mathrm{mL}(0.27$ to $4.2)$ and free thyroxine $0.84 \mathrm{ng} / \mathrm{dl}(0.93$ to 1.7$)$. The patient was noted to have features suggestive of acromegaly on physical exam with macroglossia, coarse facial features (Figure 1), enlarged hand and foot
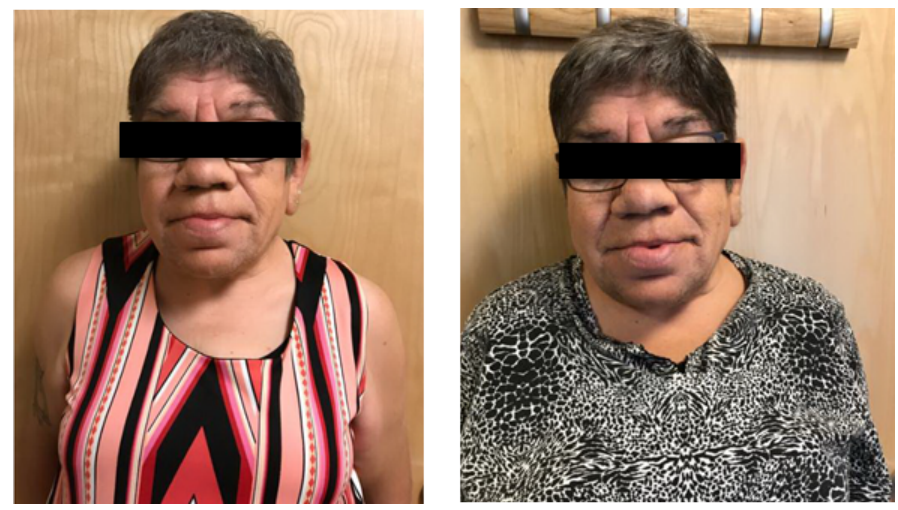

Figure 1. 57 year old female patient with diagnosis of Cantu syndrome and panhypopituitarism size. Despite acromegalic features on exam, the patient's insulin-like growth factor 1 (IGF-1) was undetectable at $<10 \mathrm{ng} / \mathrm{mL}$ (37 to 208). A magnetic resonance image (MRI) of the brain was obtained, which did not identify any abnormalities of the pituitary gland or surrounding structures. A magnetic resonance angiogram (MRA) of the brain did demonstrate occlusion of the M1 and M2 branches of the right middle cerebral artery, but without evidence of compromised hypophyseal perfusion.

On further review, the patient was found to have a complex prior medical history. She was born in 1960 at 44 weeks of gestation after a pregnancy complicated by moderate polyhydramnios. At birth her weight was elevated at 9 pounds 14 ounces, the patient had ruddy appearance with marked hypertrichosis. She also had multiple genitourinary anomalies including hydrometrococops, blind vagina without a perineal opening, ureterovesical fistula, bilateral hydronephrosis and hexadactyly. At several weeks of age she was noted to have a possible abdominal mass as well as an enlarged clitoris and labia on exam. She underwent an exploratory laparotomy in 1961 which was negative for an adrenal mass but demonstrated enlarged lymph nodes throughout the mesentery and enlargement of the right kidney. After the procedure the patient was diagnosed with adrenal cortical hyperplasia and placed on corticosteroid replacement. Of note, she was tested on multiple occasions for congenital adrenal hyperplasia and the results were negative. She was reportedly also placed on thyroid replacement at the age of three months. At the age of 15 she was evaluated for primary amenorrhea. Endocrine biochemical evaluation at that time was significant for decreased urine 17-ketosteroid $0.6 \mathrm{mg}$ (618 ), undetectable serum growth hormone $<1 \mathrm{ng} / \mathrm{mL}$, normal prolactin $11.9 \mathrm{ng} / \mathrm{mL}$, normal follicle stimulating hormone (FSH) $17 \mathrm{~m}-\mathrm{IU} / \mathrm{mL}$, normal XX karyotype, and normal barr body study. An estradiol level was not drawn at this time. She was treated with oral estrogen and progesterone replacement with reported increase in height of a halfinch, increased breast and pubic hair development as well as monthly uterine bleeding. She was lost to follow-up until 2001, at which time she presented to the Endocrine clinic for evaluation of headaches. Lab evaluation at that time was consistent with panhypopituitarism with TSH $2.46 \mathrm{mIU} / \mathrm{mL}$ (0.32 to 5), free thyroxine $0.62 \mathrm{ng} / \mathrm{dL}(0.71$ 1.85), luteinizing hormone (LH) $0.2 \mathrm{mIU} / \mathrm{mL}$ (0.6-105, depending on menstrual phase), FSH $2.1 \mathrm{mIU} / \mathrm{mL}$ (3-26, depending on menstrual phase), IGF-1 $11 \mathrm{ng} / \mathrm{mL}$ (90-360), estradiol 7 pg/mL (30-400, depending

${ }^{*}$ Correspondence to: Darshan Khangura, MD, Chief Endocrinology Fellow, University of Missouri, Columbia, USA, Tel: 573-397-9295/573-639-2235, E-mail: khangurad@health.missouri.edu

Received: March 20, 2018; Accepted: April 10, 2018; Published: April 14, 2018 
on menstrual phase), testosterone $<1 \mathrm{ng} / \mathrm{dL}$ (4-70), ACTH $36 \mathrm{pg} / \mathrm{mL}$ (6-58), cortsol level of $<1 \mathrm{ug} / \mathrm{dl}$ (6-23) with inadequate stimulation to 6 $\mathrm{ug} / \mathrm{dL}$ one hour after cosyntropin administration. The patient was lost to follow-up again from 2001 until 2016.

During the admission to the intensive care unit in 2016, the patient was treated with oral corticosteroid and thyroid hormone replacement. At post-discharge follow up the etiology of panhypopituitarism was deliberated. It was decided to refer the patient to genetics for further evaluation with thoughts that a genetic defect in one of the transcription factors or genes responsible for pituitary development could be abnormal and would explain her presentation. A chromosome study demonstrated normal karyotype, genetic testing was significant for a heterozygous novel mutation of the ABCC9 gene (c.3704C $>\mathrm{T}$, p.Ser1235Phe). This mutation is not known to be pathologic but likely represents the causative mutation in the context of her clinical presentation, which includes multiple elements of Cantú syndrome. Review of a previous chest radiograph revealed cardiomegaly, which is also an element of Cantú syndrome and she was referred to cardiology for further evaluation.

\section{Discussion}

Cantú syndrome is a rare autosomal dominant genetic disorder characterized by cardiomegaly, hypertrichosis, and osteochondrodysplasia initially described in 1982. Individuals affected by Cantú syndrome also tend to exhibit coarse facies, similar to acromegaly in appearance. The genetic basis of Cantú syndrome was elucidated by Van bon et al. and Harkalova et al. in 2012, who demonstrated that mutations in the ABCC9 gene appear to be causative of Cantú syndrome [2,3]. The ABCC9 gene encodes the channel regulation protein SUR2, which acts as part of an adenosine triphosphate-sensitive potassium channel. Mutations in the KCNJ8 gene, which encodes another component of an adenosine triphosphatesensitive potassium channel, have also been shown to cause the Cantú syndrome phenotype [4]. The exact mechanisms by which abnormalities of the channel protein lead to the observed phenotype remain unclear.

We describe a patient with Cantú syndrome diagnosed late in life following an extensive investigation of panhypopituitarism without an obvious cause. Cantú syndrome has been associated with a variety of less classical phenotypes such as ovarian agenesis [5], cerebral artery dilation [6], bronchopulmonary dysplasia [7], pericardial effusion [8], and pituitary adenoma [9]. One prior patient with a KCNJ8 mutation was found to have growth hormone deficiency without evidence of thyroid or adrenal axis involvement [10]. A patient in Italy clinically diagnosed with Cantú syndrome was diagnosed with panhypopituitarism but this patient did not have confirmed Cantú syndrome by genetic testing [11]. To the best of our knowledge, this case represents the first report of genetic testing-confirmed Cantú syndrome associated with panhypopituitarism.

The relationship between Cantú syndrome and panhypopituitarism is unclear. Our patient was placed on thyroid and adrenal replacement therapy at several weeks of age, suggesting that her hypopituitarism was present at birth and not secondarily acquired later in life. ABCC9 mutations are not a known cause of panhypopituitarism, and the genetic testing our patient underwent did not reveal an additional pathologic or possibly causative mutation $[12,13]$. Alternative causes of hypopituitarism include ischemia, mass and infiltration, which were not evident on brain MRI and MRA in this case. The patient additionally did not report any history of pituitary radiation or surgery. It remains uncertain whether our findings of co-occuring Cantú syndrome and panhypopituitarism represent unrelated co-existing findings or whether the two are mechanistically related. However, given that it is known that Cantú syndrome is associated with numerous neurologic findings including increased arterial dilation/tortuosity, white matter changes, and vascular occlusions, the relationship between panhypopituitarism and Cantú syndrome merits further examination and study.

\section{References}

1. Cantú JM, García-Cruz D, Sánchez-Corona J, Hernández A, Nazará Z (1982) A distinct osteochondrodysplasia with hypertrichosis- Individualization of a probable autosomal recessive entity. Hum Genet 60: 36-41. [Crossref]

2. Van bon BW, Gilissen C, Grange DK, Hennekam RC, Kayserili H, et al. (2012) Cantú syndrome is caused by mutations in ABCC9. Am J Hum Genet 90: 1094-1101. [Crossref]

3. Harakalova M, Van harssel JJ, Terhal PA, van Lieshout S, Duran K, et al. (2012) Dominant missense mutations in ABCC9 cause Cantú syndrome. Nat Genet 44: 793796. [Crossref]

4. Brownstein CA, Towne MC, Luquette LJ, Harris DJ, Marinakis NS, et al. (2013) Mutation of KCNJ8 in a patient with Cantú syndrome with unique vascular abnormalities - support for the role of K(ATP) channels in this condition. Eur J Med Genet 56: 678-682. [Crossref]

5. Fryssira H, Psoni S, Amenta S, et al. (2017) Cantú Syndrome Associated with Ovarian Agenesis. Mol Syndromol 8: 206-210. [Crossref]

6. Leon guerrero CR, Pathak S, Grange DK, Singh GK, Nichols CG, et al. (2016) Neurologic and neuroimaging manifestations of Cantú syndrome: A case series. Neurology 87: 270-276. [Crossref]

7. Park JY, Koo SH, Jung YJ, Lim YJ, Chung ML (2014) A patient with Cantú syndrome associated with fatal bronchopulmonary dysplasia and pulmonary hypertension. $\mathrm{Am} \mathrm{J}$ Med Genet A 164A: 2118-2120. [Crossref]

8. Grange DK, Lorch SM, Cole PL, Singh GK (2006) Cantu syndrome in a woman and her two daughters: Further confirmation of autosomal dominant inheritance and review of the cardiac manifestations. Am J Med Genet A 140: 1673-1680. [Crossref]

9. Marques P, Spencer R, Morrison PJ, Carr IM, Dang MN, et al. (2018) Cantú syndrome with coexisting familial pituitary adenoma. Endocrine 59: 677-684. [Crossref]

10. Cooper PE, Reutter H, Woelfle J, Engels H, Grange DK, et al. (2014) Cantú Syndrome Resulting from Activating Mutation in the KCNJ8 Gene. Hum mutat 35: 809-813. [Crossref]

11. Azzali A, La Spina L, Gioè D, Scalini P, Farri M, et al. (2016) A case of hypopituitarism in a patient with Cantù syndrome. Poster presented at: 55th Annual ESPE; September 10-12, 2016; Paris, France.

12. Higham CE, Johannsson G, Shalet SM (2016) Hypopituitarism. Lancet 388: 2403 2415.

13. Giordano M (2016) Genetic causes of isolated and combined pituitary hormone deficiency. Best Pract Res Clin Endocrinol Metab 30: 679-691. [Crossref]

Copyright: (C2018 John L. This is an open-access article distributed under the terms of the Creative Commons Attribution License, which permits unrestricted use, distribution, and reproduction in any medium, provided the original author and source are credited. 